


\title{
Um projecto enciclopédico e pedagógico: a Recreação Filosófica de Teodoro de Almeida
}

\author{
Autor(es): $\quad$ Domingues, Francisco Contente \\ Publicado por: Imprensa da Universidade de Coimbra \\ URL \\ persistente: \\ URI:http://hdl.handle.net/10316.2/43771 \\ DOI: \\ DOI:https://doi.org/10.14195/2183-8925_10_12
}

Accessed : $\quad$ 26-Apr-2023 15:11:55

A navegação consulta e descarregamento dos títulos inseridos nas Bibliotecas Digitais UC Digitalis, UC Pombalina e UC Impactum, pressupõem a aceitação plena e sem reservas dos Termos e Condições de Uso destas Bibliotecas Digitais, disponíveis em https://digitalis.uc.pt/pt-pt/termos.

Conforme exposto nos referidos Termos e Condições de Uso, o descarregamento de títulos de acesso restrito requer uma licença válida de autorização devendo o utilizador aceder ao(s) documento(s) a partir de um endereço de IP da instituição detentora da supramencionada licença.

Ao utilizador é apenas permitido o descarregamento para uso pessoal, pelo que o emprego do(s) título(s) descarregado(s) para outro fim, designadamente comercial, carece de autorização do respetivo autor ou editor da obra.

Na medida em que todas as obras da UC Digitalis se encontram protegidas pelo Código do Direito de Autor e Direitos Conexos e demais legislação aplicável, toda a cópia, parcial ou total, deste documento, nos casos em que é legalmente admitida, deverá conter ou fazer-se acompanhar por este aviso.

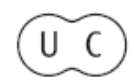


REVISTA DE HISTORIA DAS IDEIAS IO
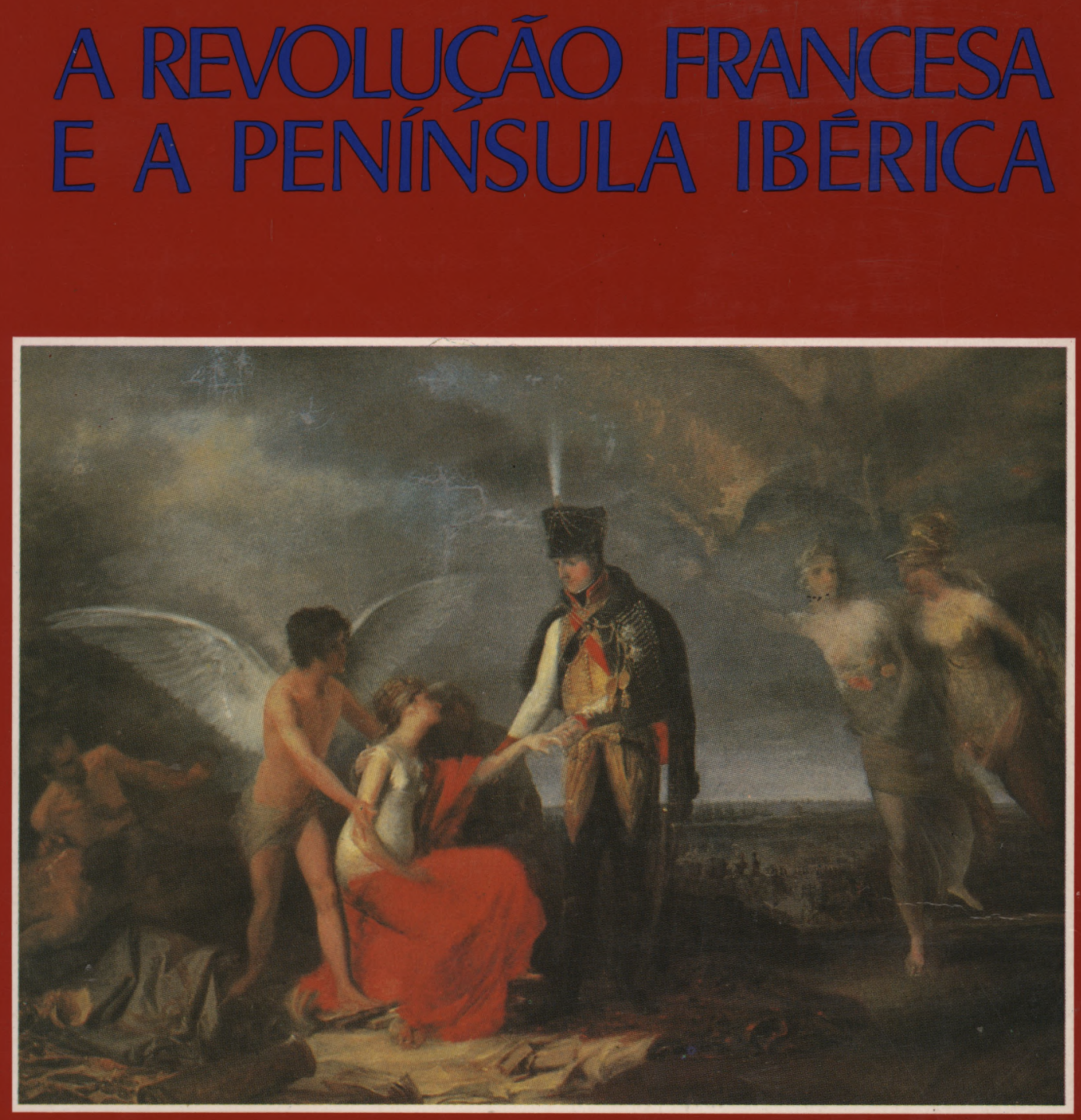

INSTITUTO DE HISTÖRIA E TEORIA DAS IDEIAS FACULDADE DE LETRAS 
FRANCISOO CONTENTE DOMINGUES *

\section{UM PROJECTO ENCICLOPÉDICO E PEDAGÓGICO: A RECREAÇÃO FILOSÓFICA DE TEODORO DE ALMEIDA}

1. Entre 1751 e 1800 saíram dos prelos os dez volumes da Recreação Filosófica do P. ${ }^{*}$ Teodoro de Almeida, projecto de condensação enciclopédica do saber arquitectado com claros intuitos pedagógicos. Por isso, logo o título completo da obra é em si mesmo um programa: Recreação Filosófica, ou diálogo sobre a filosofia natural para instrução de pessoas curiosas, que não frequentaram as aulas (1). Que circunstâncias e propósitos moveram a sua elaboração, eis o que nos propomos tratar aqui.

2. Teodoro de Almeida (1722-1804) ingressou na Congregação do Oratório a 11 de Abril de $1735\left({ }^{2}\right)$, muito antes da

* Centro de Estudos de História Contemporânea do Instituto Superior de Ciências do Trabalho e da Empresa.

(1) Foram os seguintes os anos de saída dos sucessivos volumes: I e II, 1751; III, 1752; IV, 1757; V, 1761; VI, 1762; VII, 1768; VIII, 1792; IX, 1793; X, 1800.

(2) E a data que nos é dada na biografia escrita muito provavelmente por um discípulo de nome Joaquim Dâmaso, no ano de 1830 , segundo nos leva a crer a repetida ocorrência de expressões como "neste ano de 1830" (cf. $\S 47,78,91$ e 202). O documento, ainda inédito e cuja única cópia remanescente está no A.N.T.T. ( $m s$. da Livraria, n. ${ }^{\circ}$ 2316), tem por título Vida do P. Theodoro de Almeida da Congregacão do Oratório de Lisboa, Fundador do Convento das Religiosas da Visitação de S. Maria no sitio da Junqueira, e o que mais trabalhou para de novo ser povoada a Caza do Espírito Santo da Pedreira depois de reedificada sobre as ruínas da que pelo Terremoto de 1755, e incendio, que se the seguio ficara destruida (doravante designado por Vida e citado, como é vulgar, pelo número dos parágrafos em que se divide). Sobre a questão da autoria v. Ferdinand Azevedo, Teodoro de Almeida $(1722$ -1804) and the Portuguese Enlightenment, Washington, the Catholic University of America, 1975, pp. 202-203. Reproduzimos a Vida no Apên- 
idade aconselhada pelos Estatutos $\left({ }^{3}\right)$ e gozando da protecção de um dos congregados mais influentes da época, o P. ${ }^{\circ}$ Domingues Pereira. Aí estudou filosofia durante três anos, seguidos de outros quatro dedicados à teologia, segundo o curso normal da formação no interior da Congregação. Porque eles não constavam dos curricula e os entendia necessários à sua preparação, dedicou-se paralelamente aos estudos matemáticos $\left(^{4}\right)$. E tal aproveitamento obteve de uns e outros que em 1748 era já professor substituto no triénio de filosofia, secundando o $\mathrm{P}^{\bullet}$ Luís José, para logo em 1751 ascender ao magistério da cadeira, onde se manteve até 1754. Convidado então para leccionar teologia, preferiu, ao invés de aceitar a promoção, continuar ligado à divulgação do que fora até então o seu objecto primacial de estudo: a filosofia experimental $\left(^{5}\right)$.

Não obstante a posição a que se veio a alcandorar no panorama cultural de Setecentos, a Congregação do Oratório não nascera com uma vocação pedagógica marcada. A junção dos congregados (clérigos seculares sem qualquer obrigação de votos) visava em primeiro lugar, e no entender do promotor da iniciativa, o P. ${ }^{\text {e }}$ Bartolomeu de Quental, o prosseguimento e a difusão de um novo entendimento da vivência religiosa; e depois, a assistência aos sectores mais carenciados da população - idosos, indigentes, doentes $\left(^{(}\right)$.

dice Documental da nossa dissertação de Mestrado apresentada em 1986 à Faculdade de Ciências Sociais e Humanas da Universidade Nova de Lisboa, com o título Teodoro de Almeida (1722-1804). Subsídios para uma biografia, elaborada sob a direcção do Prof. Dr. José Esteves Pereira.

(3) Dezoito anos, segundo o n. 22 dos Estatutos da Congregação dos Clérigos do Oratório de N. Senhora da Assumpção (publicados por J.S. da Silva Dias, A Congregação do Oratorio. Regulamentos Primitivos, Coimbra, Universidade - Instituto de Estudos Filosóficos, 1966). Admitiam-se excepções a este requisito se os candidatos manifestassem «tal virtude. talento e prestimon que levasse os responsáveis a aceitar o ingresso - que no caso de Teodoro de Almeida não foi isento de algumas renitências. segundo a Vida.

(4) Vida, § 14.

(5) Vida, \& 29.

( $)$ Sobre o P.e Bartolomeu de Quental (1627-1689) e a origem da Congregação v. J.S. da Silva Dias, $o b$. cit.; idem, «A Congregação do Oratório, Sua traça primitiva», Colóquio, n.o 44 (1967), pp. 65-67; Eugénio dos Santos, $O$ Oratório no Norte de Portugal. Contribuição para o estudo da vida religiosa e social, Porto, I.N.I.C., 1982, I Parte; Jean Girodon, Lettres du Père Bartolomeu do Quental a la Congrégation de l'Oratoire de Braga (29.IX.1685-22.XI.1698), Paris, F.C.G.-C.C.P., 1973; idem, "Les Origines de l'Oratoire de Portugal». Bulletin des Etudes Portugaises, nouv. série, t. 28/29 (1967-8). pp. 145-162; e a primeira parte da nossa dissertação, citada na n. 2. 
Eram as próprias condições de ingresso que pareciam dispensar a existência de estudos básicos no seu interior, pela idade e formação requerida aos futuros congregados $\left({ }^{7}\right)$. Todavia, a entrada em número cada vez maior de jovens que a não possuíam (tal como Teodoro de Almeida), levou à criação de aulas destinadas não só aos congregados como a quem a elas quisesse assistir, quer para aprender as primeiras letras, quer para prosseguir e aprofundar os seus estudos $\left(^{8}\right)$.

Não sabemos em que altura exacta entraram em funcionamento, ou a data em que abriram as suas portas para o exterior as aulas dos chamados estudos inferiores. Os cursos de filosofia $€$ teologia tiveram o seu início pela década de 1670 , com toda a probabilidade $\left({ }^{9}\right)$, e registaram logo um sucesso notável. Em boa parte graças à valia pedagógica do P. ${ }^{\circledR}$ Jacob Bernardes, que regeu a partir de 1696 o terceiro curso de filosofia, a afluência de alunos levou esta cadeira a funcionar ao mesmo tempo que a teologia, na casa oratoriana do Porto, ao invés da costumada sucessão $\left({ }^{10}\right)$.

Este sucesso pedagógico e a consciência do mesmo levaram inevitavelmente ao choque com a Companhia de Jesus, dada a posição hegemónica que esta detinha no aparelho educacional português. Aos oratorianos não podia deixar de desagradar a subalternização dos seus métodos de ensino: e por isso se derime no domínio estrito dos critérios pedagógicos o conflito que os opõe aos inacianos no início do século XVIII, como afirma J. S. da Silva Dias (11) e o parece confirmar o facto de

(7) V. o n. 22 dos Estatutos citados na nt. 3.

(8) Sobre os estudos na Congregação v. Ester Pinheiro da Fonseca Soares Costa, Os Estudos na Congregação do Oratório em Portugal desde a sua Fundação até 1750, dissertação de licenciatura dactilografada, Coimbra, Faculdade de Letras, 1964; e Maria Amélia Mota Capitão, Anti-Escolasticismo em Portugal na Congregação do Oratório (século $X V I I I)$, dissertação de licenciatura dactilografada, Lisboa, Faculdade de Letras, 1957. Recolhem-se elementos preciosos, embora quase sempre dispersamente, nas obras de Eugénio dos Santos e Ferdinand Azevedo, ia citadas. e, entre outros, nas de J.S. da Silva Dias, António Alberto Banha de Andrade e Rómulo de Carvalho (de quem se verá em particular a recente História do Ensino em Portugal, Lisboa F.C.G. 1986). E fundamental o estudo de Rui Grácio, «História da História da Educação em Portugal: 1945-1978", Cultura-História e Filosofia, vol. II (1983), pp. 135-184.

(9) Em 1675, segundo Ester Soares Costa, ob. cit., p. 72; com o triénio do P. Diogo Tinoco, em 1679 ou 1682, de acordo com A.A. Banha de Andrade, Contributos para a História da Mentalidade Pedagógica Portuguesa, Lisboa, INCM, 1981, p. 411.

(10) Eugénio dos Santos. ob. cit., p. 294.

(11) Por esta altura "existiria, quando muito, uma simnles divergência de esquemas pedagógicos» entre uns e outros (J.S. da Silva Dias, Portugal e a Cultura Europeia, Sep. de Biblos, Coimbra, 1953, p. 143). 


\section{Revista de História das Ideias}

não se encontrar qualquer manifestação das razões de natureza bem distinta (dizendo respeito aos próprios conteúdos dos programas) que mais tarde caracterizarão novas confrontações.

Este conflito é também institucional, naturalmente. Os oratorianos pretendem ver os exames feitos na casa-mãe da Congregação, a casa do Espírito Santo em Lisboa, considerados válidos e suficientes para a matrícula na Universidade em vez de, como até então, terem de ser repetidos no Colégio das Artes, em Coimbra. Obtêm-no com a provisão régia de 16 de Outubro de 1716; mas devem ter-se sucedido intensas manobras de bastidores de forma que o rei veio a repôr a obrigatoriedade da repetição no Colégio das Artes, a 17 de Outubro de 1724. Foi porém sol de pouca dura, e a suficiência dos exames prestados

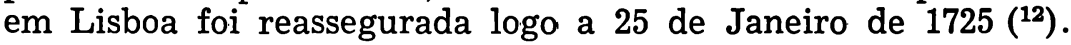

Desta forma a Companhia de Jesus perdeu a exclusividade na orientação dos estudos que, mesmo fora da sua rede de colégios, obedeciam grosso modo ao padrão tradicional por ela traçado. Os oratorianos vão ainda alargar o privilégio conseguido ao hospício das Necessidades e às Congregações do Porto e de Braga, já no reinado de D. José I ( $\left.{ }^{13}\right)$.

Por detrás dos congregados, a sombra protectora de D. João $\mathrm{V}$ exerceu uma tutela que explica muito do êxito do Oratório. O monarca declarou-se protector da Congregação a 7 de Fevereiro de 1709, e foi a ela buscar o P. ${ }^{\circ}$ Francisco Pedroso para seu confessor em 1712, depois da morte do padre que o assistia espiritualmente, jesuíta como todos que o precederam. Francisco Pedroso veio a ter um enorme ascendente sobre o rei, tal como o seu sucessor, o P. Domingues Pereira, precisamente o protector de Teodoro de Almeida. Para além da resolução favorável do diferendo relativo à questão dos exames, a dádiva maior veio a 9 de Fevereiro de 1745: o hospício das Necessidades, dotado de uma biblioteca com 30000 volumes além de ưma dotação anual de 220000 réis para a ir completando; e de um gabinete de física experimental, louvado na altura pela excelência do seu equipamento. Aos néris pedia-se apenas que ensinassem as primeiras letras e o catecismo aos habitantes das redondezas, e bem assim gramática; retórica, filosofia e teologia (14).

(12) V. os textos destas disposições in Teófilo Braga, História da Universidade de Coimbra, vol. III, Lisboa, Acad. Real das Sciencias, 1898. nas pp. 274, 275-276 e 276-278.

(13) Sobre esta questão v. as pp. 274-280 da obra citada atrás. XXV-XXX.

(14) Jean Girodon, Lettres du Père Bartolomeu do Quental, pp. 


\section{A Recreação Filosófica de Teodoro de Almeida}

3. O que pretendia pois Teodoro de Almeida ao lançar a público, por esta altura, os primeiros volumes da sua Recreação Filosófica? Na realidade, bem mais do que a sua simples publicação pode sugerir, numa primeira apreciação.

O projecto inicial da obra compreendia apenas seis volumes, e será cumprido em 1762 , em circunstâncias já bem diferentes das que assistiram ao seu início, como veremos à frente. Estas mais de duas mil páginas tratam sucessivamente de assuntos tão diversos como a gravidade e o peso dos corpos, o movimento, a luz, o fogo, o ar, a água, a anatomia humana, os brutos, os planetas, os astros ou o globo terrestre - entre outros. Abrangendo portanto o largo espectro das ciências físico-naturais, a filosofia natural que se tornaria num dos eixos centrais das polémicas culturais a que assistiu a segunda metade do século XVIII.

A vinda a lume da Recreação Filosófica não representa de facto a mera continuidade da actividade pedagógica do seu jovem autor. $\mathrm{Na}$ verdade, ela constitui peça fundamental de uma dessas polémicas, a da filosofia experimental, que conjuntamente com a que se seguiu à publicação do Verdadeiro Método de Estudar $\left({ }^{15}\right)$, e a da gramática latina $\left({ }^{18}\right)$, eclodiram com fragor na década de 1750 . No seu conjunto ilustram bem a conflitualidade que opôs o statu quo vigente e as sensibilidades que apostavam na modernidade cultural - choque que assumiu matizes os mais diversos, e cujos termos e protagonistas não são amiúde os que têm sido como tal identificados em perspectivas que hoje são já clássicas na percepção das linhas de força fundamentais da cultura portuguesa no período $\left({ }^{17}\right)$.

Todavia ele foi uma realidade, e bem impressiva: punha-se em causa a funcionalidade da visão do mundo (do mundo físico, da natureza) tal qual era passível de ser apreendida nos

(15) V. A.A. Banha de Andrade, Vernei e a Cultura do Seu Tempo, Coimbra, Acta Universitatis Conimbrigensis, 1966.

(16) V. Ebion de Lima, "Os Oratorianos e a Polémica da Gramática Latina no Século XVIII", Boletim da Biblioteca da Universidade de Coimbra, vol. 36 (1981), pp. 57-72. Para este ou qualquer outro dos problemas da cultura portuguesa no período em causa, recorrer-se-á ainda ao estudo de J.S. da Silva Dias, Portugal e a Cultura Europeia, Coimbra, 1953.

(17) J.S. da Silva Dias acaba de publicar um trabalho fulcral, a este propósito, pela colocação dos problemas que trata: "Cultura e obstáculo epistemológico do Renascimento ao Iluminismo em Portugal». in A Abertura do Mundo. Estudos de História dos Descobrimentos Europeus em Homenagem a Luís de Albuquerque, org. de Francisco Contente Domingues e Luís Filipe Barreto, vol. I, Lisboa, Presença, 1987, pp. 41-52 
circuitos normais de ensino, contrapondo-se-lhe a proposta e os métodos pedagógicos de quem entendia estar essa mesma mundividência irremediavelmente ultrapassada pelo curso das novas ideias, particularmente na esfera que hoje diríamos científico-filosófica. Esboçavam-se assim novas modalidades do confronto entre Antigos e Modernos, entre os defensores da escolástica e os arautos das concepções filosóficas seis e setecentistas que a equacionavam.

Os oratorianos reclamaram para si a primazia na recepção e na divulgação da filosofia experimental (exageradamente, embora), particularmente com o magistério de João Baptista, professor de filosofia na Congregação (onde teve como primeiro discípulo Teodoro de Almeida) e autor de uma obra fundamental neste domínio, pela influência que veio a ter entre os congregados: trata-se da Philosophia aristotelica restituta et illustrata quà experimentis, quà ratiociniis nuper inventis $\left({ }^{18}\right)$, da qual a parte segunda, dedicada à física, é a que particularmente nos interessa. João Baptista defende aí a possibilidade de ultrapassar os ensinamentos da escolástica pelo retorno ao que seria o verdadeiro magistério aristotélico, e no qual incorpora ainda alguns dos resultados essenciais do devir filosófico-científico moderno. Desta forma definiu com o seu eclectismo filosófico uma ruptura parcial mas nem por isso menos firme com o ensino tradicional $\left({ }^{19}\right)$, que abandona em 1737 ao iniciar o ensino da física moderna nas aulas da Congregação $\left({ }^{20}\right)$ e às quais a abertura do gabinete de física das Necessidades virá a dar ainda maior projecção.

$\mathrm{Na}$ sua senda, alguns dos professores oratorianos apostaram decisivamente na divulgação da filosofia experimental.

(18) 2 vols., Lisboa, 1748.

(19) Não são muitos nem muito recentes os trabalhos dedicados à vida e obra do P. João Baptista. Há que começar por J.S. da Silva Dias, Portugal e a Cultura Europeia; pelo artigo que o mesmo autor dedicou ao néri no Grande Dicionário da Literatura Portuguesa e da Teoria Literária, dir. J.J. Cochofel, vol. I (e único), Lisboa, Iniciativas Editoriais, 1977, pp. 589-590; e por João Pereira Gomes. «João Baptista e os peripatéticos». Brotéria, vol. XXXIV (1944), pp. 121-137 (este último autor é um dos que pontificaram - com Domingos Maurício Gomes dos Santos e A.A. Banha de Andrade - entre quantos, sobretudo nas décadas de 1940 e 1950, publicaram algumas dezenas de artigos, mormente na revista Brotéria. com o fito de mostrar que o ensino filosófico dos jesuítas estava perfeitamente a par do que a Europa ia vendo medrar no tocante a novos sistemas filosófico-científicos. Por isso. os seus pontos de vista são por vezes radicalmente distintos dos de J.S. da Silva Dias).

(20) J.S. da Silva Dias, "Cultura e obstáculo epistemológico do Renascimento ao Iluminismo em Portugal», p. 48. 
Sob a influência de João Baptista, embora afastando-se do mestre no essencial das suas formulações próprias, foi o eclectismo filosófico que serviu também de sustentáculo à doutrina expendida por Teodoro de Almeida nestes primeiros volumes da Recreação Filosófica. Objectivavam a escolástica, explícita e negativamente, tida aqui como responsável pelo atraso que caracterizava a situação dos estudos em Portugal.

A Recreação Filosófica é um libelo dos Modernos contra os Antigos, um ensaio de afirmação da validade de todo um novo saber. Não está aqui em causa, evidentemente, a possibilidade de uma exposição circunstanciada do sistema do mundo explanado por Teodoro de Almeida (com correcções parciais ao longo dos muitos anos em que escreveu, embora congruente nas suas linhas gerais), mas sim o facto de ser esta a grande obra de projecção enciclopédica que nos meados do século XVIII propunha a um vasto público um saber mais actualizado do que era passível de ser apreendido nas escolas; e fazendo-o, para mais, com notório êxito. A Recreação Filosófica é um sucesso editorial, como aliás o foram boa parte dos livros do seu autor ${ }^{21}$ ).

A obra está escrita em português, em diálogo, e numa linguagem simples e acessível. Tratava-se de uma aposta pedagógica que partia do princípio de que o saber não era exclusivo do universo fechado pelos muros escolares, nem devia ficar confinado aos que dominavam o latim. Ao saber dos Antigos contrapunham os Modernos não apenas novas ideias: mas também a sua acessibilidade e capacidade explicativa para a compreensão dos fenómenos naturais. Ao saber longamente aprendido nos livros contrapunha-se a experiência que demonstrava uma realidade física e o enunciado simples e claro das leis que regiam o curso da Natureza. A alternativa que se pretendia opôr à escolástica não se fundava apenas no conteúdo, fazendo de igual modo recurso da forma como os seus ensinamentos eram transmitidos (independentemente das diferentes possibilidades que se colocavam para quem quisesse sair dos trilhos da «filosofia perene»).

Ao iniciar a publicação da Recreação Filosófica no ano em que principia a reger o seu primeiro curso, Teodoro de Almeida inscreve-se decididamente no campo dos que pugnam pela renovação. Não tendo sido o primeiro, terá todavia mais

(21) Em vida do autor, os primeiros seis volumes foram repetidamente editados (quatro ou cinco vezes), sempre depois de refundidos, acrescentados e actualizados. 
eficácia que qualquer outro na promoção do seu projecto e das suas ideias. $O$ jovem professor do Oratório insere-se bem dentro do que era já nesta altura a tradição pedagógica da Congregação, que por seu turno sairá reforçada com este novo concurso.

4. E com efeito na década de 1740 que, no dizer de J. S. da Silva Dias, a publicação quase concomitante de quatro obras arremete decisivamente contra o primado epistemológico da escolástica. São elas: a Lógica Racional, Geométrica e Analítica, de Manuel de Azevedo Fortes (1744); o Verdadeiro Método de Estudar, de Luís António Verney (1746); a tradução, resumida para dois, dos nove volumes do Teatro Crítico Universal do espanhol Benito Jerónimo Feijoo (1746-1748); e a Philosophia Aristotelica Restituta de João Baptista (1748) $\left({ }^{22}\right)$. Se têm uma repercussão múltipla, a nível erudito, a questão põe-se igualmente ao nível da vulgarização. $E$ nesse particular a acção da Congregação teve um papel decisivo.

De facto, são os congregados que de uma forma mais sistemática se propõem a divulgar a filosofia experimental. Primeiro com os cursos de João Baptista e a publicação da sua obra magistral. Depois com as Conferências de Filosofia Experimental, que o mesmo João Baptista animou nas Necessidades, abertas a um público que acorria a ouvir descrever os fenómenos naturais ilustrados com o recurso à experimentação. Funcionavam como uma espécie de cursos abertos, e sabemos que se terão realizado desde $1752\left({ }^{23}\right)$. O próprio monarca e os infantes lá se deslocaram a ouvir Teodoro de Almeida, que no ano seguinte secundou o seu mestre na orientação das conferências, e teriam mesmo chegado a participar nas experiências realizadas $\left({ }^{24}\right)$. O sucesso foi tal que o conferencista se chegou a queixar do elevado número de presenças, por obstar a que todos vissem as experiências nas melhores condições $\left({ }^{25}\right)$.

(22) J.S. da Silva Dias, ob. cit., p. 48. Seria a predominância da explicação científica do terramoto do $10^{\circ}$ de Novembro que marcaria em 1755 o termo do obstáculo epistemológico ao advento das novas ideias (idem, ibidem, p. 49).

(23) Conhecida há muito a participação de Teodoro de Almeida nestas conferências, só agora A.A. Banha de Andrade revelou que a iniciativa das mesmas pertencia a João Baptista. V. deste autor $A R e$ forma Pombalina dos Estudos Secundários (1759-1771). 1. vol., 1.: Parte, Coimbra, Acta Universitatis Conimbrigensis, 1981, p. 44.

(24) Vida, § 1; Carta Exortatoria aos PP. da Companhia de Jesus da Provincia de Portugal, B.N., Cód. 8974, fl. 214v.

(25) A.A. Banha de Andrade, ob. cit., p. 52. 


\section{A Recreação Filosófica de Teodoro de Almeida}

Os ciclos de conferências não se devem ter realizado em 1754 e 1755, mas logo depois foram retomados, e agora também em Braga $\left({ }^{26}\right)$.

Paralelamente Teodoro de Almeida ia regendo o seu curso filosófico, cujas postilas em latim chegaram até nós incompletas $\left({ }^{27}\right)$. Publicará depois, ainda em latim, novo curso $\left({ }^{28}\right)$, o que ilustra à evidência o sentido da publicação da Recreação Filosófica, inserida neste todo e dirigida a esse mesmo público que acorria às conferências e a quantos se interessassem pelos novos ensinamentos: os que «não frequentavam as aulas» ou que, tendo-o feito, pretendiam renovar e alargar o horizonte dos seus conhecimentos. $\mathrm{E}$ ia promovendo sessões particulares em casas de fidalgos, para as quais levava algumas máquinas cujo funcionamento mostrava aos circunstantes - pelo que foi aliás duramente criticado $\left({ }^{29}\right)$.

$\mathrm{Na}$ década de 1750 , apoiados pelo seu êxito pedagógico e pelas condições de que dispunham, os oratorianos são de facto os principais responsáveis pela divulgação das novas ideias científico-filosóficas em Portugal. O projecto enciclopédico da Recreação Filosófica não é senão um corolário lógico das outras iniciativas que acabámos de referir, e que no seu conjunto deram grande popularidade aos néris. Quando em 1758 sai a 3. ${ }^{2}$ edição do tomo I, além de conter uma história da filosofia que era nova em relação às edições anteriores da obra, ela é igualmente testemunho de um optimismo exultante pelo curso que o seu autor via as coisas tomarem:

«nunca em Portugal se vio tão bem estabelecida, e radicada a sã Filozofia, como no tempo presente.... Já não anda escondida, solitaria, e perseguida, mas aparece em publico,

(26) Idem, ibidem, p. 52.

(27) Conhecemos os manuscritos das partes segunda e terceira do Cursus philosophicus, actualmente na Biblioteca Pública de Evora (CXVIII-1-12 e CXVIII-1-13).

(28) Theodori de Almeida Congregations Oratori Olisiponensi Sacerdotis, Physicarum Institutuonum, Libri X. Ad usum Scholarum, 3 vols., Lisboa, 1785.

(29) Por Emídio Lúcio Crispo, pseudónimo sob o qual se esconde o autor de uma das cartas que verberaram a oração de abertura da Academia de Ciências de Lisboa, proferida por Teodoro de Almeida a 4 de Julho de 1780. e na qual refere de passagem esses tempos (na década de 1750) em que o oratoriano promovia sessões particulares: cf. Carta em crítica a Oração do P.e Teodoro d'Almeida na abertura da Acadiemia, Biblioteca Geral da Universidade de Coimbra, ms. 1504. Há referências ao facto noutra carta de crítica. E evidente que a certa altura estas manifestações tinham também um carácter lúdico e tornou-se moda entre certos círculos sociais esta atenção pelo experimentalismo, sem que isso tenha correspondência num interesse científico, real. 
com tanto sequito, e tão pompozo acompanhamento, que mais me parece que triunfa, do que peleja. Vejo tentar uma e outra ves as experiencias, vejo manejar as Maquinas com cuidado, vejo consultar as importantes leis da Mecanica, vejo entim tormar calculos matemáticos;.... Já agora no descobrımento da verdade escondida, não se fia o entendimento só da lús da razão, procura á forsa de repetidos golpes de experiencias, tirar de dentro da mesma natureza uma nova lús que o alumeie, para caminhar seguro» $\left({ }^{30}\right)$.

5. Não é evidentemente aceitável a radical identificação entre Modernos e oratorianos, Antigos e jesuítas. De entre estes últimos podemos destacar até nomes claramente apostados numa divulgaçăo em tudo paralela à que Teodoro de Almeida empreende: é bem o caso do P. ${ }^{\ominus}$ Inácio Monteiro, autor de um Compêndio dos Elementos de Matemática onde é flagrante a similitude entre a sua aposta pedagógica e a do néri, a concordância de pontos de vista em múltiplas questões ${ }^{31}$ ). Porém, o certo é que Monteiro teve problemas dentro da Companhia, e o mesmo sucedeu a outros inacianos que mostraram propensão a aceitar as consequências do devir do pensamento filosófico dos dois séculos anteriores. Na realidade, assegurar a congruência do aristotelismo e da escolástica significava assegurar a validade pedagógica do ensino ministrado nos noviciados, nos seminários e nos colégios da Companhia - que só no continente ascendiam a 22. $\mathrm{E}$ se há sinais evidentes de que se tinha clara noção da mudança dos tempos, dentro da Companhia, no que a este nível diz respeito, não é menos verdade que no essencial se procurava manter - se tinha de tentar manter este ensino dentro das linhas mestras que o norteavam.

A 7 de Maio de 1746 um edital do reitor do Colégio das Artes de Coimbra determinava que

«nos exames, ou Lições, Concluzões públicas, ou particulares se-não insine defenção ou opiniões novas pouco recebidas, ou inuteis para o estudo das Sciencias mayores como são as de Renato, Descartes, Gacendo, Neptono, e outro, e nomeadamente qualquer Sciencia, que defenda os actos de Epicuro, ou negue as realidades dos accidentes Eucharisticos ou outras quaisquer concluzõis oppostas ao sistema de Aristoteles, o qual néstas escólas se-deve seguir» (32).

(30) Teodoro de Almeida, Recreação Filosofica, tomo I, terceira impressão muito mais aumentada, e correcta, que as precedentes, Lisboa. Na Oficina de Miguel Rodrigues, 1758, "Dedicatória».

(31) Inácio Monteiro, Compêndio dos Elementos de Matemática, 2 vols., Coimbra, no Real Colégio das Artes da Companhia de Jesus, 17541756.

(32) Publicado por Joaquim de Carvalho no Boletim da Biblioteca 


\section{A Recreação Filosófica de Teodoro de Almeida}

Oito anos volvidos, é certo que o Elenchus Quaestionum se afasta do Ratio Sudiorum que vinha de 1599; mas o Elenchus nada cede de essencial aos Modernos, embora seja evidente a inevitabilidade de atender a algumas das realidades da nova física $\left.{ }^{33}\right)$.

No plano das ideias, de qualquer forma, a questão está longe de se poder apreender com facilidade: só um conhecimento profundo do conteúdo dos diversos cursos ministrados bem como das obras dos seus professores, e de quantos se debruçaram então sobre idênticas matérias, pode permitir chegar a uma resposta conclusiva. Já não é assim no plano político-institucional, onde se verifica facilmente que a aç̧ão pedagógica da Congregação do Oratório equacionou inequivocamente a posição da Companhia de Jesus, tanto mais que a primeira dispôs quase sempre dos favores régios, com tudo o que isso implicou a nível de benesses materiais e outorga de privilégios.

Não admira pois que a contestação ao magistério oratoriano (quer dizer de alguns dos mestres do Oratório) viesse rapidamente a manifestar-se. Assumiu várias vertentes, mas aqui interessar-nos-á a réplica à Recreação Filosófica.

Logo em 1752 saiu a lume a Palinódia Manifesta, de autor anónimo mas seguramente inaciano $\left({ }^{34}\right)$, a contrapor os argumentor da escolástica sobre duas questões fulcrais tratadas no 2. volume da Recreação: a alma dos brutos e os acidentes da eucarista.

A primeira objectou-se no sentido em que Teodoro de Almeida foi claro ao perfilhar a ideia do animal-máquina de René Descartes $\left({ }^{35}\right)$. A segunda objectou-se igualmente a filiação nos sistemas eucarísticos cartesianos que a Recreação decalca dos argumentos já aduzidos por João Baptista, como afirma João Pereira Gomes ${ }^{\left({ }^{36}\right)}$. Não se lhe pôde opôr uma

da Universidade de Coimbra, vol. XX (1951), pp. 170-172. Trecho citado na p. 171.

(33) Sobre o Elenchus v. A.A. Banha de Andrade, "O 'Elenchus Ouaestionum' de 1754", in Contrihutos para a História da Mentalidade Pedagógica Portuguesa. pp. 263-334. Na senda do que foi a orientacão geral dos seus estudos. este autor vê no Elenchus uma grande aceitacão das ideias modernas, então com pleno curso nas escolas da Companhia de Jesus em Portugal.

(34) Famião Ferrão Philalethe, Palinndia Manifesta, Sevilha, en la Imprenta de António Buccaferro, s/d (1752; o local de impressão e o impressor são naturalmente fictícios).

(35) Compare-se Teodoro de Almeida, Recreação Filosófica, Tomo II, Lisboa. 1751. np. 352-369 a René Descartes, Discurso do Método, trad. de Newton de Macedo, Lisboa Sá da Costa, 1976, pp. 45-6.

(36) João Pereira Crnmes. "Sistemas encarísticos na filosofia portuguesa do século XVIII», Lumen, X (1946), p. 220. 


\section{Revista de História das Ideias}

resposta una, porque ela não existe dentro dos sistemas de tipo escolástico-peripatético; mas Teodoro de Almeida viu-se na necessidade premente de responder porque o problema envolvia a crença na transubstanciação, ponto fulcral do catolicismo, e a sugestão de qualquer desviacionismo ao dogma, mesmo que subtilmente velada, não permitia o silêncio.

A resposta virá na $2 .^{\mathrm{a}}$ edição do tomo $\mathrm{I}$, e no tomo $\mathrm{V}$ Teodoro de Almeida reafirmará as suas posições: índice evidente da sua confiança, portanto sinal claro dos tempos que iam correndo.

A Palinódia Manifesta tem por objectivo acentuar as vertentes filosóficas e teológicas do problema. A polémica não era nova: o que é aqui novo, e daí a contradição imediata, é que se explicava pela primeira vez em vernáculo que o sistema eucarístico da escolástica não era único; e que, portanto, a visão do mundo físico dada pelos Modernos era em tudo conforme à religião, ao contrário do que pretendiam os seus detractores.

Foi contra a Recreação que se traduziu a Origem Antiga da Física Moderna, do abade Noel Regnault, em 1753. O tradutor utilizou o pseudónimo de João Carlos da Silva, mas não custa a crer que fosse também loiolita.

O enciclopedismo do projecto inicial da Recreação Filosófica não se limitava a pretender dar ao leitor uma visão geral do entendimento do mundo físico segundo a óptica dos Modernos. Afirmava fundamentalmente que o sistema escolástico se devia substituir por um eclectismo filosófico onde não havia lugar para se seguir qualquer escola em particular; e que isso se fazia sem prejuízo da harmonia da filosofia natural com a espiritualidade. Pelo contrário: o pleno conhecimento da Natureza revelava à evidência que Deus, e só Deus, fora o obreiro de semelhante perfeição. O bom filósofo natural é essencialmente e antes do mais um bom cristão. Toda a filosofia do oratoriano assenta neste postulado, e se revê nele $\left(^{37}\right)$.

Não é impunemente que as suas obras espirituais ganham tanto prestígio e projecção como as de divulgação científica, pois que atrás do pedagogo e do divulgador está sempre o homem da Igreja.

(37) A documentação do que fica dito encontra-se na nossa dissertação citada na nt. 2. Centra-se na análise destas ideias a comunicação que apresentámos ao seminário Do Antigo Regime ao Liberalismo: Perspectivas de Síntese (1750-1850), em curso de publicação sob o título «Ilustração e catolicismo. 1750-1800». De algum modo, estas duas comunicações completam-se entre si. 


\section{A Recreação Filosófica de Teodoro de Almeida}

6. As circunstâncias mudarão. Em 1760 a Companhia de Jesus fora já expulsa, e a Congregação do Oratório parece ter - caminho livre para tomar ela um lugar preponderante na vida cultural do país. Até que nesse ano quatro das suas figuras mais destacadas serão forçadas ao exílio interno. Contam-se entre elas João Baptista, que como censor do Santo Ofício quis impedir a publicação de uma obra do intendente geral da Polícia, Inácio Ferreira do Souto, cujo fito era a justificação teórica do regalismo que norteava a praxis política de Sebastião José de Carvalho e Melo; e o seu discípulo dilecto Teodoro de Almeida. além de João Chevalier (figura prestigiada pelos seus trabalhos científicos, nomeadamente no domínio da astronomia) ( ${ }^{38}$ ) e Clemente Alexandrino (irmão de João Baptista), estes provavelmente por serem solidários com o anti-regalismo do primeiro.

Foi o prenúncio das dificuldades que estavam para vir: em 1768 a Congregação é quase manietada, e o Conde de Oeiras planeava mesmo a sua extinção pura e simples, para o que chegou a redigir o respectivo decreto $\left({ }^{39}\right)$.

Nestes oito anos que passou no Porto e antes de se ver forcado a fugir nara o estrangeiro. Tendoro de Almeida redigiu os tomos V e VI da Recreação Filosófica, concluindo assim o seu plano expositivo da filosofia natural na óptica do naturalismo cristão que balizava todas as suas concepcões. $\mathbf{E}$ no ano em que saiu de Portugal publicou também a primeira extensão ao projecto inicial desta obra, com o tomo VI que trata da lógica, isto é, da filosofia racional $\left({ }^{40}\right)$.

Depois de um longo hiato, três volumes mais completarão este grande monumento enciclopédico da segunda metade de Setecentos, iniciando com a sua temática a mudança de direcção do sentido primeiro das preocupacões do seu autor: dizem respeito à metafísica (tomo VIII, 1792), à Harmonia da Razão $e$ da Religião, título com que aparece o tomo IX em 1793, e ainda à filosofia moral ou ética, com o tomo X (1800).

$\mathrm{Na}$ realidade, se a Congregação nunca conseguiu recuperar no seu conjunto da oposição política que lhe moveu Carvalho e Melo a partir de 1760, perdeu também por isso o lugar que

(38) V. a propósito e em primeiro lugar Rómulo de Carvalho, A Astronomia em Portugal no século XVIII, Lisboa, I.C.L.P., 1985, pp. 69-74 em particular.

(39) Vida, § 15.

(40) E talvez um dos volumes em que o oratoriano se mostra mais devedor dos escritos de outrém, nomeadamente do $\mathrm{De} R e$ Logica de Verney (1751) e da sua matriz fundamental, a lógica de Port-Royal. 
ocupava na ribalta da cena cultural portuguesa $\left({ }^{41}\right)$. E, concomitantemente, Teodoro de Almeida verificou o sucesso de consequências que não pensara ou previra da extensão dos estudos de filosofia natural, tal como os entendera. A profunda harmonização da visão do mundo físico e do entendimento que dele pode ter a razão humana com a fé religiosa é afirmada primeiro em situação de convicção da sua superioridade sobre a escolástica, nos meados do século e no planeamento inicial da Recreação Filosófica. Quarenta anos depois, o seu tomo IX é já claramente ilustrativo de uma atitude essencialmente defensiva que se prolonga para as próprias concepções político-sociais que lhe são consequentes ${ }^{\left({ }^{4}\right)}$.

A aceitação do ideal iluminista por Teodoro de Almeida é clara na sua aposta pedagógica, na crença na razão e no progresso dos conhecimentos do Homem. Mas a partir do momento em que isso porá em causa o que toma sempre como referente primeiro (a fé), tornar-se-á adversário intransigente dos desenvolvimentos que entende radicais de um ideário só possível de ser aceite na sua solução mais moderada; e que pauta sem desfalecimento cinquenta anos de trabalho apostado na divulgação, pela escrita e pela palavra, de um iluminismo católico mais bem representado em Portugal na sua obra que na de qualquer outro de quantos trilharam a mesma via.

(41) São variados e complexos os motivos de perseguição do ministro de $\mathrm{D}$. José quer à Congregação, quér a Teodoro de Almeida. Abordámos o assunto na nossa dissertação de mestrado, em mais de um lugar. Alguns deles foram tratados por A.A. Banha de Andrade, nomeadamente em dois dos artigos inclusos na colectânea Contributos para a História da Mentalidade Pedagógica Portuguesa, pp. $419-433$ e $435-490$.

(42) Teodoro de Almeida deixa nitidamente recortada a sua preocupação fulcral na "Dedicatória» e na "Prefação» da Theologia Natural da Recreação Filosófica, ou Harmonia da Razão e da Religião, tomo IX, Lisboa, 1793. 